\title{
Expansion of the Research Path of Chinese Film Theory in the Digital Age
}

\author{
Dunmin Shi ${ }^{1, *}$ \\ ${ }^{1}$ School of Theatre, Film and Television, Communication University of China, CUC, Beijing, China \\ *Corresponding author. Email: shidunmin0109@163.com
}

\begin{abstract}
In the era of globalization and digital culture marked by the Internet, big data, cloud computing, virtual reality, artificial intelligence, etc., technological revolution and media innovation have prompted the development of current film theory to turn to the focus on ontology again, and rethink "What are the movies of the digital era?" and "What might the movie become?". At the same time, the digital age has also brought about a shift in the paradigm of film research, recognizing the characteristics and advantages of films in the digital age from the perspective of the evolution of the film itself, combining new paths of film research methods, and exploring new possibilities and values for the development of Chinese film. It is expected that film theory can form a new interactive relationship with film creation in the digital era and play a leading role of theory so as to build benign film ecology.
\end{abstract}

\section{Keywords: Chinese film theory, the digital age, path of film research}

\section{INTRODUCTION}

Since the $21 \mathrm{st}$ century, in the context of globalization and digital culture marked by the Internet, big data, cloud computing, virtual reality, artificial intelligence, etc., technological revolutions and media innovations have triggered many new phenomena and propositions in movies. We start asking again, "What are movies in the digital age?" and "What could movies do?". The resulting anxiety about the end of the film itself greatly promotes the current theoretical research of the film in the process of constantly exploring the self-identity of the film and the boundaries involved. Digital technology and image reproduction technology have changed the filming and production methods of films, but also shaken the proposition and aesthetic foundation of classic film theory. The development of the Internet and media innovation have expanded the form and spread of films. The development of technology and media has made the image writing move towards true freedom, and it has also turned film theory research to focus on film ontology again, providing a new path for Chinese film theory research in the new era and cultural context.

\section{RESEARCH ON THE EVOLUTION LAW OF FILMS IN THE DIGITAL INTERNET ERA}

\section{A. Research path from media perspective}

Internet and media innovation make the media characteristics of movies more and more complex. Films in the digital Internet era are not only in the technical media, they even have the characteristics of being mediated. In today's highly mediated life, the blending and interaction of movies and people's lives are getting deeper and deeper. The current film development not only needs to examine the changes of itself as a new form of media, but also needs to handle the symbiotic relationship between the film and other media. At present, the film research path based on media perspective mainly focuses on the following aspects.

1) The ontology of film media: As one of the essential attributes of film, media is essential to examine and understand film and film art from the perspective of media ontology. It contains different dimensions such as the film as the medium and the film medium itself. At the same time, the transformation and transformation of the media and the development of Chinese film also have a certain isomorphic relationship. For example, $\mathrm{Xu}$ Lin looks at the development of Chinese movies from the perspective of media change [1], and Liu Yang analyzes the commercial transformation of contemporary Chinese movies from the perspective of media transformation theory [2].

2) Film media morphology: The Internet and digital technologies are constantly spawning new forms of movie media, such as microfilms, Internet films, surveillance films, desktop films, and database films. Facing the new film media form, film theory urgently needs to innovate the discourse system. 
3) Film media platform theory: Digital technology and the Internet have provided a new platform for film media. The emergence of the integration of films and games, interactive images, short video applications on mobile phones, barrage, online reviews, fan culture, and multi-screen linkage has not only brought together more developments for film Multi-resources, but also have greatly expanded the space of film creation. Besides, it will generate new audiences. In the "postfilm" era, multiple media platforms can be used to achieve the extension of film production value and promote the development of the film industry.

4) Film media fusion theory: With the emergence of new types of dynamic audiovisual media such as video games, museum images, network videos, and mobile phone short videos, the film has been integrated into the trend of "media integration", and it has entered a stage in which multiple dynamic audiovisual media mutually melt symbiotic. Media fusion reflects the objective trend of multi-functional integration of media in the digital age, blurs the boundaries of traditional media forms, and produces new audio-visual media such as film and television integration and video-network integration. At present, the phenomenon of cross-media attributes of films, new audiovisual media and other phenomena are looking forward to theoretical responses. The media advantages and possibilities of films in the digital era need to be further explored. Under the background of media fusion, audiences need to be repositioned and research on "focus strategies".

\section{B. Research path from technology perspective}

Since the birth of the film more than 100 years, the development of film and technology has always been inseparable. Especially in the digital age, the technological media innovation of films has created huge potential for the development of films. The development of film media technology will directly affect the position of Chinese films in the world film landscape. Today, under the guidance and drive of demand, technology, and capital, the global film industry has achieved important breakthroughs in production technology, projection technology, communication technology, and research methods. China's film industry has introduced a number of world-class high-tech film production and projection equipment, and the standard is gradually in line with international standards, but in terms of independent research and development of key technologies, deepening of high-tech applications, leading formulation of technical standards, deepening of technical aesthetics, etc. are still insufficient. The development of Chinese films in the digital age must grasp China's current advantages in 5G, Internet and other scientific and technological fields, taking the promotion of movie technology innovation and hightech application as the starting point, carrying out film technology innovation, and effectively improve the production level of films and the film viewing experience in theaters to maximize the advantages of films in the digital age marked by high and new technology. At the same time, we should also focus on the deepening of the application of high-tech film technology in local films to achieve deep integration with Chinese stories and Chinese film aesthetics. The research topics of film technology are now mainly concentrated in the following aspects:

1) Specific film technology: Specific research paths for film technology, including film big data, film database construction, digital humanities, digital technology, film audio-visual effects, digital virtual technology, 3D, 4K, 8K, 120 frames, VR, interactive imaging, future imaging, artificial intelligence, etc. In the digital age, movies have evolved from an audiovisual experience to an immersive comprehensive experience. The future development of movies will inevitably rely on high-tech innovation. In addition to studying the innovation of film technology itself, the study of film theory should focus on discussing the interrelationship between technology and film form, content, concept, aesthetics, etc.

2) Film technology philosophy: Reflection on film technology itself and research on film technology philosophy might be a new research path. In the digital age, the new ecology, artificial intelligence and other topics brought about by film and high technology may become the focus of its philosophical issues, which may not only lead to a rethinking of "movie", but also will lead to the new perception of "human". [3]

3) Reconstructing the aesthetics of film technology: The development of film technology will inevitably bring about changes in aesthetic concepts. Digital technology has created more image wonders, enriched the experience of movies, and enhanced the entertainment of movies. At the same time, the relationship between film and reality has also changed. From the "photographic ontology" in the film age to the "digital imaging ontology" in the digital age, movies can not only enhance reality, but also virtual past or future. In addition, the boundary between film and life in the digital age has been broken. Digitization and visualization have become people's daily life and communication methods. Therefore, how to reconstruct the film aesthetics with Chinese characteristics in the digital age is an important theoretical proposition. 


\section{EXCAVATING THE FUNCTION AND VALUE OF FILM IN DIGITAL AGE BASED ON LOCAL POSITION}

After understanding and reflecting on "what is the movie in the digital age" and the characteristics and advantages of the movie in the digital age, we also need to implant the movie in the digital age into the local culture of China to grasp its particularity. "Chinese experience" as the boundary set by national identity and community is being confirmed by the fact that the film is constantly being generated. [4]

\section{A. Constructing a film aesthetic system with Chinese style}

How to reconstruct the film aesthetic concept in the digital age and how to construct the film aesthetic system with Chinese style is an important part of the Chinese film theory in the digital age. Digital virtual technology has shaken the film reality aesthetics based on "photographic image ontology" in the film era, allowing us to return to the exploration of the relationship between image and reality. In the process of Chinese films going to the world, we should also fully show the national cultural characteristics of Chinese films with the attitude of "each is beautiful in its own way, beauty in beauty, beauty in unity with the rest of the world", and combine digital technology with traditional Chinese aesthetic concepts to unify artistic expression and Chinese style.

\section{B. Chinese films should tell Chinese stories and spread the Chinese voice}

General Secretary Xi Jinping pointed out: "Telling Chinese stories is a proposition of the times, and telling Chinese stories well is the mission of the times." As an important social media and artistic medium, films in the digital age should pay more attention to reality and express the people's voices and concerns as well as delivery Chinese value. Based on the practice, expressing practice, and promoting practice as the main breakthroughs in the development of Chinese film, strengthen the film's attention to the "Chinese experience" of China's grand changes, that is, the evolution of the Chinese people's values or spiritual world.

The combination of movies in the digital age and Chinese stories is one of the key propositions of theoretical studies of Chinese movies. In recent years, it has been a hot spot for creation and theory. For example, the combination of mainstream blockbuster films and Chinese stories has resulted in a number of new mainstream blockbuster films such as "War Wolf" series, "Chinese Captain", "Wandering Earth", "Me and My Motherland", etc. Both the box office and the public praise have achieved a bumper harvest, promoting the benign interaction between the film industry and the mainstream values, bridging the gap between commercial films and the main melody since the 1980s, and showing the harmonious symbiotic relationship between the political ontology concepts and industrial ontology concepts of Chinese movies in the digital age. The success of the "War Wolf" series shows the cultural charm of Chinese hero films. The patriotic spirit and military image conveyed by the film have been generally accepted by the audience. Another example is the return of realism in genre films, such as "Blizzard is Coming", "Detonator" and other genre movies. The model of genre films is combined with Chinese real problems to express the anxiety and mental predicament during the period of social transformation. There are also art films such as "Twenty-two" and "Carnival" that focus on marginalized groups and reflect on social issues.

The Chinese film in the digital age should seek development in the balance of industry and art, market and culture. The return of realism and the storytelling of Chinese stories are one of the important ways for Chinese film to improve its quality.

\section{Enhancing the soft power of film culture and giving play to the leading role of film culture}

At present, Chinese movies have entered a new stage of "50 billion yuan" at the box office. Whether from the box office revenue, the number of screens, movie viewing groups, or from the perspective of production technology and projection technology, Chinese movies have shown a great momentum. However, Chinese films still have shortcomings in terms of artistic innovation, social communication, aesthetic radiation, and value guidance. At present, the development mode of Chinese movies is changing from speed and scale to quality and efficiency, and upgrading quality and efficiency is the core goal. How to improve the comprehensive competitiveness, artistic originality, media communication and cultural leadership of Chinese films in the digital age has become a key point in the development of Chinese film theory.

\section{ESTABLISHING THE RESEARCH METHOD OF FILM THEORY IN THE DIGITAL AGE}

\section{A. A research path combining quantitative and qualitative research by means of digital research}

Traditional Chinese film research relies heavily on the traditional methods of the humanities, mostly text analysis, qualitative research, and empirical (questionnaire, field survey), quantitative and other social science research methods are insufficient. To a large extent, this determines that film theory has long been limited to more grand discourse resources such as philosophy, aesthetics, and cultural studies.[5] 
In today's highly medialized life, the complexity of the film media brought about by the Internet and media innovation and the deep interaction between film and people's lives also require that the research of film theory must expand horizons, transform thinking, and make full use of big data, databases, artificial intelligence and other technical means to carry out empirical research. These means of Internet and digital technology can not only help us find hot theoretical issues, but also have unique advantages in objective understanding of film phenomena and revealing the laws of film. In recent years, "big data" has played a great role in the research of films under the influence of complex variables, such as long time and multi-text. "After analyzing the content of the box office, ratings, and Internet click-through rates, the text is converted into numbers under a unified and stable classification standard and principle, and it presents an objective, systematic, and comprehensive abstract state." [6]

The progress of research means has also changed the paradigm and thinking of film research. Digital mobile devices and the Internet have brought a larger audience to movies, and audiences' demands and expectations for movies have become increasingly diversified. Therefore, the research focus of current film theory should be shifted from film creators and film texts to audiences, and then reverse thinking from the perspectives of audience, acceptance and communication to study creators and film texts, so as to enhance the effectiveness of theoretical research.

Although quantitative research has absolute advantages in data mining and clarifying phenomena, the development of theory cannot be separated from qualitative research. The understanding of the essential laws of films must be based on the sorting out and description of various phenomena, but film research can only rise to the height of theoretical laws through rational analysis and sublimation. Therefore, the film theory research in the digital Internet era should make full use of the advantages of digital research methods and combine quantitative and qualitative research in depth, so as to have stronger explanatory power and vitality.

\section{B. Interdisciplinary research path of discipline integration}

Media integration is an important feature of the digital Internet era. Discipline integration is an inevitable trend of media integration development to a certain stage, and it is also determined by the trend of the convergence of the development of subject knowledge such as drama, Chinese opera, radio, television, communication, and new media. Therefore, the film theory research in the "post-film" era can only better deal with the impact of the future development of technology, media and culture on the film if we strive to cross the boundaries between disciplines, learn from each other, integrate and communicate with each other, and learn from each other's advantages.

Discipline connectivity is also an important starting point for original discourse and academic innovation in the digital age. For example, through the exploration of the naming of new film forms and their aesthetic characteristics, the proposition and argumentation of art propositions, the creation and argumentation of proper terms for new media art, and VR, AR technology based on the creative practice and theory summary of virtual art etc., to rich the construction of Chinese film discourse system.

\section{The path of constructing the subjectivity of Chinese film based on Chinese experience}

Since the reform and opening up, accompanied by the wave of economic globalization, Chinese films have gradually integrated into the world film industry system in the process of continuously building the national film subjectivity, with a view to making Chinese films stand in the world film forest and make China for the development of world films contribution. Against this background, the shaping of subjectivity has also become a new object of thinking for the research and practice of Chinese cinema.

The focus on the subjectivity of the film is, on the one hand, a reflection on the establishment of an equal dialogue between East and West cultures in the development of the national film; on the other hand, the study of Chinese film theory has long been dominated by Western theoretical discourse The relationship with the Chinese film text is becoming increasingly tense, and I look forward to providing a new solution to the study of Chinese film theory in order to obtain a benign interaction between film theory and film creation.

Based on this, the current development of Chinese film theory should be guided by Xi Jinping's new era socialism with Chinese characteristics, with the goal of promoting the construction of a community of human destiny, promoting the exchange of different civilizations and mutual learning, and building an original film theory based on locality, blending Chinese and foreign Discourse system. Sort out and construct the thoughts, theories, viewpoints, methods, etc. corresponding to the theoretical system of Chinese film, and form a thinking system, academic foundation, spiritual soul, and artistic style that can deeply express Chinese values. Only by rooting in the unique history of Chinese local film development, basing on the current status of Chinese film creation and the future development trend of world film, and refining one's own theoretical propositions, can we create new concepts, new categories, and new concepts that are easily understood and accepted by the international community It can be stated that constructing an original 
theory with Chinese characteristics in the new era, and responding to the needs of the times, local film creation and audience, can further build a "Chinese film school" in an international context, reflecting the selfconfidence of contemporary Chinese film theory.

\section{CONCLUSION}

Throughout the history of the development of Chinese movies, we have improved our understanding of the ontology in the continuous fusion and innovation of movies. In the digital Internet era, technological revolution and media innovation have enriched the connotation and extension of movies. Therefore, Chinese film theory must re-understand what is the film in the digital age? Then fully explore the possibility and value of movies in the digital age. The research path proposed in this article aims to provide some possible ideas for the theoretical research of digital generation film, so that we can better grasp the essence and advantages of the current film.

\section{References}

[1] X. Lin, "The Evolution of Chinese Films from the Perspective of Media Revolution” , 2007(in Chinese)

[2] L. Yang, "Media Transformation: A Look at the Commercial transformation of Contemporary Chinese films from the fifth and sixth generation directors", 2008.(in Chinese)

[3] C. Xiaoyun, "Film Research: Reconstruction, Continuation and Turn" Film art 2020(01). (in Chinese)

[4] D. Yaping, "The Evolution, Self-Reflection and Trend of Chinese Film Research in the 70 Years - Also on the Writing of 'The History of Contemporary Chinese Film Art (19492017)"” Art studies 2019(03). (in Chinese)

[5] C. Linxia, "A Review of Film Theory and Its Development" Contemporary Cinema 2016(09).(in Chinese)

[6] C. Linxia, "A Review of Film Theory and Its Development" Contemporary Cinema 2016(09).(in Chinese) 